\title{
MINIMIZING LOSSES DURING NATURAL GAS TRANSPORTATION
}

\section{POBEREZHNY Lyubomyr ${ }^{1}$, HRYTSANCHUK Andrij ${ }^{1}$, OKIPNYI Igor ${ }^{2}$, POBEREZHNA Liubov ${ }^{3}$, STANETSKY Andrij ${ }^{1}$, FEDCHYSHYN Nadiya $^{4}$}

\author{
${ }^{1}$ Ivano-Frankivsk National Technical University of Oil \& Gas, Karpatska str. 15, Ivano-Frankivsk, \\ Ukraine, e-mail: lubomyrpoberezhny@gmail.com \\ ${ }^{2}$ Ternopil Ivan Pul'uj National Technical University, Ruska str. 56, Ternopil, \\ Ukraine, e - mail: i.okipnyi@gmail.com \\ ${ }^{3}$ Ivano-Frankivsk National Medical University, Galytska str. 2, Ivano-Frankivsk, \\ Ukraine,e-mail: physics@ifnmu.edu.ua \\ ${ }^{4}$ I. Horbachevsky Ternopil State Medical University, Maidan Voli 1, \\ Ukraine,e-mail:snt@tu.edu.te.ua
}

\begin{abstract}
The processes of supplying natural gas are accompanied by significant losses. In this regard, the complex problem of minimizing losses and improving the efficiency of energy use is very relevant. Steel pipelines for transportation of oil and gas often cross the tracks or are located parallel to the lines of electric power transmission lines of alternating current. Most dangerous from the corrosive point of view of the combination of the chemical composition of the soil electrolyte and the vagal current density were established.
\end{abstract}

KEYWORDS: growth rate of corrosion rate, corrosion damage, model environments, low-alloy steel, carbon steel.

\section{Introduction}

Providing continuous operation of the pipeline transport, taking into account all its features, is a priority and necessary task of avoiding accidents and failures that lead to loss of pipe integrity. The break in the provision of natural gas for industrial facilities is causing a decrease in the country's economic performance, as well as the welfare and high standard of living of the country's population.

A significant part of accidents $(80 \%)$ on pipelines is a consequence of the course of various forms of corrosion: general corrosion, cracked corrosion under discarded coating, point corrosion, corrosion cracking under stress, etc. As a result of corrosion, there is a decrease in the section of the pipeline, which increases the ecological risk of further exploitation of such metal structures and actualizes the problem of estimating their residual resource. The problem is also exacerbated by the fact that in the operation of the pipeline, as a rule, is exposed simultaneously to mechanical loads (deformation), wear and corrosion-active media [1]. Such a joint action can cause accelerated corrosion-mechanical destruction of pipelines, which is significantly intensified under the influence of fields of wandering currents. Steel pipelines for transportation of oil and gas often cross the tracks or are located parallel to the lines of electric power transmission lines of alternating current. Located in close proximity to the paths of electric trains, which use alternating current as power. In addition, in urban settlements, much of the metal pipelines are located near the alternating current sources, and pipelines can be used as earthing switches. Therefore, in order to select reliable and optimal natural-to-end transportation routes, it is necessary to assess the risk of de-icing due to soil corrosion and to investigate the effect of wandering alternating current on this process. 
Analysis of publications on the topic of research. According to the EGIG report, the highest risk of gas pipeline failures as a result of corrosion is due to long service life and a small thickness of the pipe wall (Fig. 1).

One of the most dangerous types of corrosion is electro corrosion. The reports of corrosion anomalies on gas pipelines have been actively registered in Europe in the early 80's of the last century. In particular, in 1986, corrosion losses in gas pipelines were registered in Germany via an alternating current of $162 / 3$ and $50 \mathrm{~Hz}$ [2]. In 1987, a similar situation arose in Switzerland [3]. Further such cases have been registered in the USA, Canada and France. Moreover, as it was reported in [4-6], the rate of drainage of the pipe wall due to corrosion of the alternating current is quite high and is, accordingly, $0.8 \div 1.4 \mathrm{~mm} / \mathrm{year}$. In all these publications it was noted that the exploited pipelines were under cathodic protection, and the values of cathode protection meet the necessary criteria.

It is most likely that some of the previous cases of corrosion could also be related to the consequences of $\mathrm{AC}$, but this was omitted due to the lack of a database and a small amount of information on this type of corrosion. One of the reasons why these corrosion cases were not related to the effect of alternating current could be the belief that cathodic protection completely eliminates the influence of alternating current.
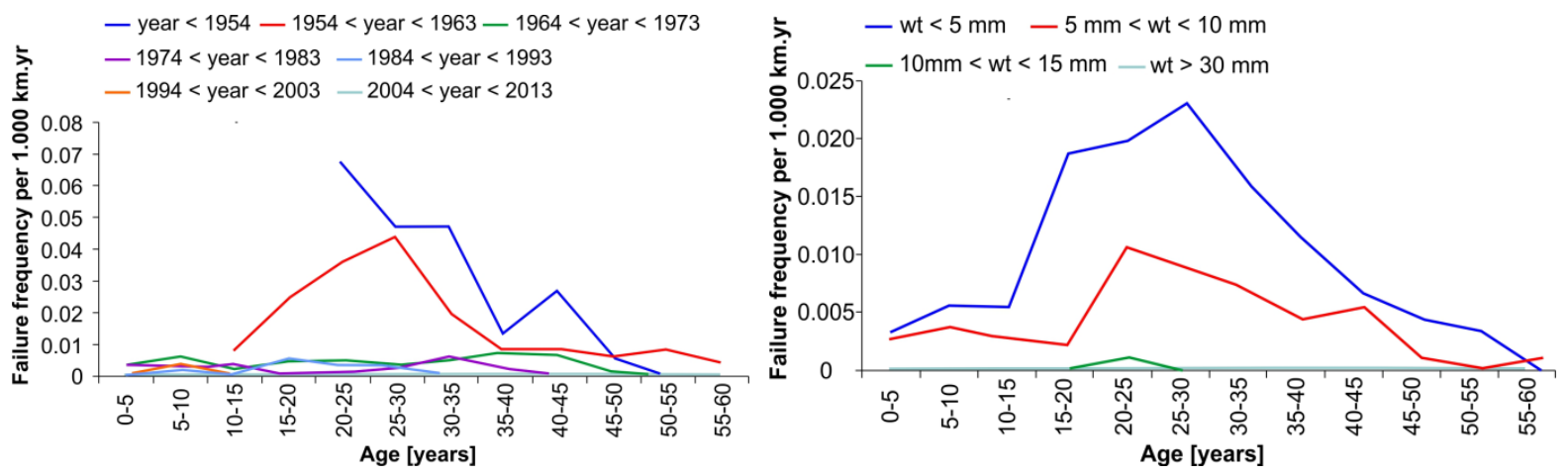

Fig. 1 The dependence of the failures' frequency on the gas pipelines from construction year (a) and wall thickness (wt) (b)

It is known that each type of corrosion can be identified by the characteristic products of corrosion, corrosion damage to the surface and the consequences of their effects. There were no such characteristics for alternating current corrosion at that time. Required information that associates the consequences of the AC impact on the pipelines has accumulated in the process of extensive laboratory and field research. In particular, lesions that arise under the action of an alternating current [7] can be described as follows:

- the formation of a rigid dome in the form of a cluster of soil and products of corrosion;

- corrosion with alternating current leads to the formation of ulcers with characteristic rounded edges;

- $\quad$ the size of ulcers is usually always larger than the size of the coating defect.

Such anomalies are found on a pipeline established in Los Angeles in 1992 (Fig. 2, a). The dome was fixed on the pipeline from corrosion products, and corrosion losses were $20 \%$. Similar damage was detected due to the planned shurfing of the protective coating on underground pipelines in Houston (Fig. 2, b). Shurfing showed that the rate of electro corrosion is dangerously high - the loss of metal in the thickness of the wall of the pipe for 4 years was 30\% [8-9]. Another section of the pipeline revealed similar anomalies, but the corrosion losses were significantly higher than the previous defect and amounted to $50 \%$. 


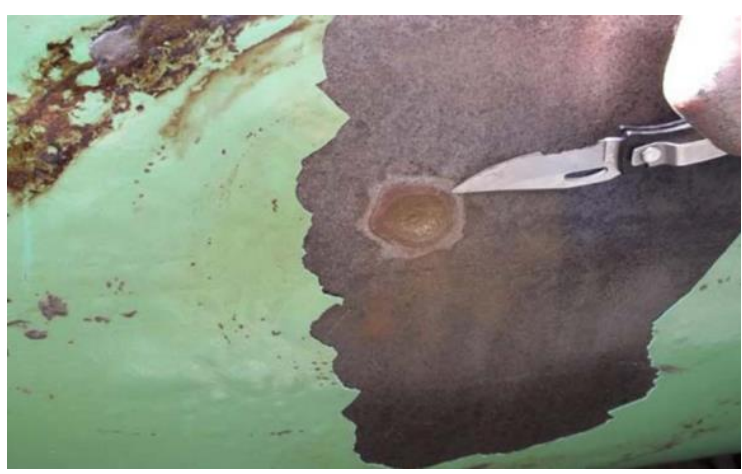

a

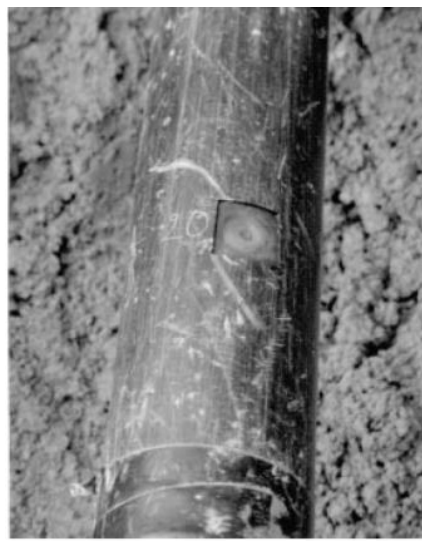

$\mathrm{c}$

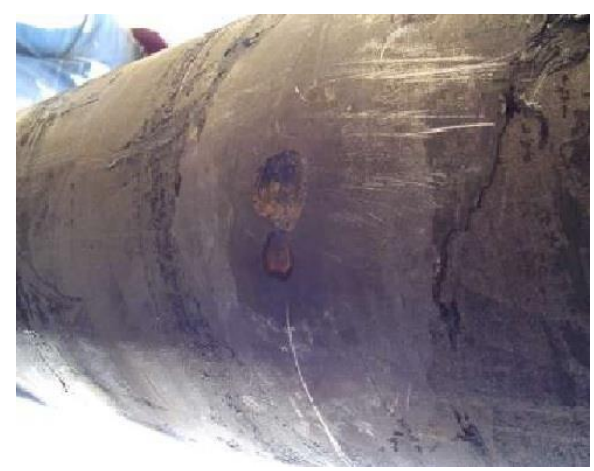

b

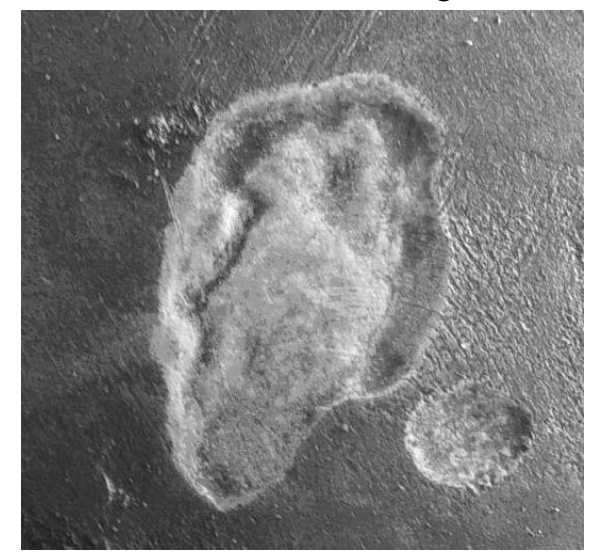

d

Fig. 2 Characterized corrosion damage by alternating current in Los Angeles (a), Houston (b), south of France (c) and Gdansk (d)

As a result of the flaw detection of the protective coating of the gas pipeline in France in 1993, 31 corrosion damage was detected. The pipeline with a diameter of $100 \mathrm{~mm}$ and a length of $6 \mathrm{~km}$ had a parallel run with $400 \mathrm{kV}$ overhead lines in length of $3 \mathrm{~km}$ (Fig. 2, c). The depth of corrosion damage was from 0.1 to $0.8 \mathrm{~mm}$.

Although data on corrosion losses caused by alternating current was accumulated for the past 40 years overseas NACE standards do not take into account the danger of the alternating current influence on the underground lines and exclude the possibility of significant corrosion damage focusing on the use of passive and active protection, which prevents the corrosive effect of $\mathrm{AC}[10]$.The criterion of danger based on in-vitro studies identified alternating current density of $30 \mathrm{~A} / \mathrm{m}^{2}$ as causing corrosion. This value depends on such factors as the frequency of the current composition of the soil electrolyte at the interface, the resistance of the soil around the defect coverage [11]. Earlier in 1995, there were developed by the international Association SGRA methodical recommendations for the study of corrosion under the action of $\mathrm{AC}$ and identified the key factors of the operational environment that affect the occurrence of this type of corrosion $[12,13]$.

In addition directly on the pipeline, which is located in the zone of influence of AC the same damage was discovered. The pipeline was reconstructed in 2005, that is, there have been applied bituminous protective coatings in place of its detachment. Before the reconstruction there has been found 30 corrosion damage with depth up to $3 \mathrm{~mm}$ on the pipeline after 20 years of operation, caused by alternating current. After renovation in a shorter period (5 years) was diagnosed with 53 similar defects (Fig. 2, d).That is, when extending the lifetime of the pipelines due to deterioration of the material of pipelines, the risk of corrosion under the action of the alternating current increases. 


\section{$2 \quad$ Problem statement}

To ensure reliable and uninterrupted gas transportation, pipeline control at all stages of the life cycle is required, as well as optimal logistic solutions that will avoid laying pipelines in soils of high corrosion activity and through areas of increased geodynamic activity. Appropriate regulatory documents have been developed to control the design, construction, and protection processes, in which, based on the analysis of laboratory and field experimental studies, appropriate criteria and rules are specified.

The rapid development of the energy systems of the leading countries of the world and the increase of the share of electric current in the energy balance requires the construction of new high-voltage transmission lines. Such lines can pass over or near the steel pipelines and cause the flow of induced current, which significantly accelerates and localizes corrosion damage. To date, there is no clear definition of "safe" level of induced current density. In Russian standard GOST 9.602-2005 [14], in accordance with paragraph 4.8, an alternating current of $10 \mathrm{~A} / \mathrm{m} 2$ on the auxiliary electrode is dangerous. Similarly to DSTU B V.2.5-29: 2006 the operation of this standard does not apply to main pipelines. In connection with the adoption of the Federal Law on Technical Regulation it was allowed to establish its industry standards regarding the critical value of the density of alternating current under the influence of highvoltage transmission lines (VLPP). According to these norms, the critical current density is in the range from 10 to $30 \mathrm{~A} / \mathrm{m}^{2}$.

In the national Polish standards BN-85/2320-01 [15] and PN-90/E-05030/01 [16], the risk of corrosion due to waving alternating current is not included at all, while the issue of the risk of corrosion caused by constant vagal currents is widely represented. It is now recognized that the alternating current flowing to underground pipelines can be a cause for a significant acceleration of corrosion. The assessment of corrosion danger depends on the density of the current. In PN-EN 12954: 2004 [17], the probability of corrosion can not be taken into account if the AC density of the protective coating defect of $1 \mathrm{~cm}^{2}$ is less than $30 \mathrm{~A} / \mathrm{m}^{2}$.

In 2005, the CEN/TS 15280: 2006 norm [18] appeared on the basis of data accumulated in the course of experimental research on the assessment of the risk of corrosion by alternating current of electrochemical protection pipelines. The probability of corrosion is estimated by the current density measured on the probe with an area of $1 \mathrm{~cm}^{2}$, respectively, for:

- Jkor $<30 \mathrm{~A} / \mathrm{m}^{2}$ - slight or missing corrosion;

- Jorkward 30 to $100 \mathrm{~A} / \mathrm{m}^{2}$ - average corrosion rate;

- Jkor> $100 \mathrm{~A} / \mathrm{m}^{2}$ - high corrosion risk.

Thus, there is no definite single critical threshold of current density. The magnitude of this critical value is controversial and to a large extent dependent on the impact of the operating environment. It should be noted separately that low and medium pressure pipelines are most often operated without cathodic protection and the AC power problem is more acute for them than for main pipelines operated from using cathodic protection.

The purpose of the work is to study the effect of induced AC on corrosion of steel gas pipelines in order to minimize the losses of natural gas during transportation.

\section{$3 \quad$ Materials and methods}

The research object selected steel pipes 17GS and 3. From this steel, low and medium pressure pipelines are manufactured. Samples of simple form were used, since they easily 
remove corrosion products and easily measure their area (Fig. 3). For the same series of studies, all specimen were the same.
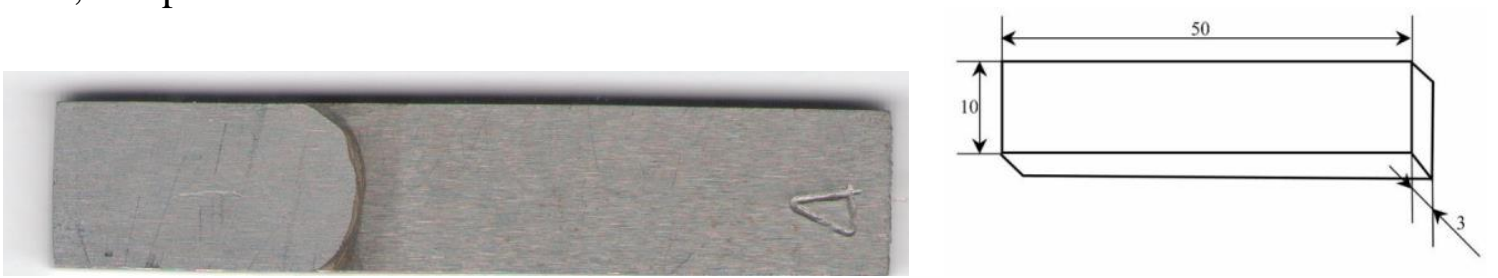

Fig. 3 Samples for conducting corrosion tests under the action of alternating current in model environments simulating the composition of the soil electrolyte

Since in the presence of defects in the protective coating there is a direct contact of the material of the pipe with soil electrolyte, the data on its concentration and composition are extremely important in order to predict the flow processes at the defect site. Under underground steel corrosion, the general kinetic patterns of corrosion are determined solely by the properties of the electrode layer of soil electrolyte - anionic composition, concentration, $\mathrm{pH}$. For pilot studies, model environments have been selected based on aqueous solutions of the corresponding salts and acids, since the latter simulate and reproduce the flow of processes occurring under operating conditions. Conducting experimental studies on wet soil is inappropriate because it does not provide the reproducibility of the experiment when conducting a series of experiments in the same environment and does not allow correctly to determine the average value for each experiment series.

At the previous stage of the research the laws of electro corrosion in neutral ground electrolytes were studied [19]. In this work, corrosion in acid mineralized soils was studied and appropriate model environments were selected (Table 1).

Tab. 1 Composition of model environments for corrosion tests

\begin{tabular}{|c|c|c|c|c|}
\hline \multirow{2}{*}{$№ \mathrm{MC}$} & \multicolumn{4}{|c|}{ Concentration, mol/l } \\
\cline { 2 - 5 } & $\mathrm{NaCl}$ & $\mathrm{Na}_{2} \mathrm{SO}_{4}$ & $\mathrm{HCl}$ & $\mathrm{H}_{2} \mathrm{SO}_{4}$ \\
\hline 1 & 0.01 & - & 0.00001 & - \\
\hline 2 & 0.05 & - & 0.0001 & - \\
\hline 3 & 0.1 & - & 0.001 & - \\
\hline 4 & 0.005 & 0.005 & - & 0.000005 \\
\hline 5 & 0.025 & 0.025 & - & 0.00005 \\
\hline 6 & 0.05 & 0.05 & - & 0.005 \\
\hline
\end{tabular}

The choice of acidic environments is due to the continued operation of existing pipelines. From literature [20, 21] it is known about the special sensitivity of the material of the pipelines at the late stage of exploitation to hydrogen overstock, the risk of its occurrence in acidic environments is the greatest. The tests were carried out by immersing the samples in pairs in a model environment, followed by an overvoltage of 5, 10, 15 and $20 \mathrm{~A} / \mathrm{m}^{2}$. At the same time, a control sample was tested (without over-current). The rate of corrosion $\mathrm{K}$ was determined gravimetrically. To evaluate the impact of alternating current, the indicator $\Delta K$ was used.

$$
\Delta K=\frac{K_{1}-K_{0}}{K_{0}} \cdot 100 \%
$$

where $K_{0}$ is the speed of corrosion of the control sample, $K_{1}$ the rate of corrosion at the overlay of the current 


\section{$4 \quad$ Results and their discussion}

Studies have shown (Fig. 4) that an increase in the concentration of acid (ME3), which leads to a decrease in the $\mathrm{pH}$ environment (ME1 - $\mathrm{pH}=5, \mathrm{ME} 2-\mathrm{pH}=4, \mathrm{ME} 3-\mathrm{pH}=3$ ) leads to an increase in the corrosion rate in all three environments. Moreover, the difference is more perceivable in the transition from ME1 to ME2 than in the transition from ME2 to ME3. In the case of changing the $\mathrm{pH}$ environment, it should be noted that for ME1 in the cathode half-life of the alternating current is more characteristic of oxygen depolarization and the occurrence of corrosion will occur in a mechanism similar to the neutral chloride environments ME1-3. But due to the increase in the concentration of chlorine ions, their adsorption on the metal surface occurs more perceivable in the places where defects are formed in the protective coating and more actively dissolving the protective oxide film. With a sufficient amount of oxygen, that is, with good aeration, the recovery of depolarizers will increase, which will increase the rate of general corrosion. In ME1, for a current density of 5 $\mathrm{A} / \mathrm{m}^{2}$, the corrosion rate is $9.2 \%$, and in ME7 $12.2 \%$, respectively, with the same salt concentration.
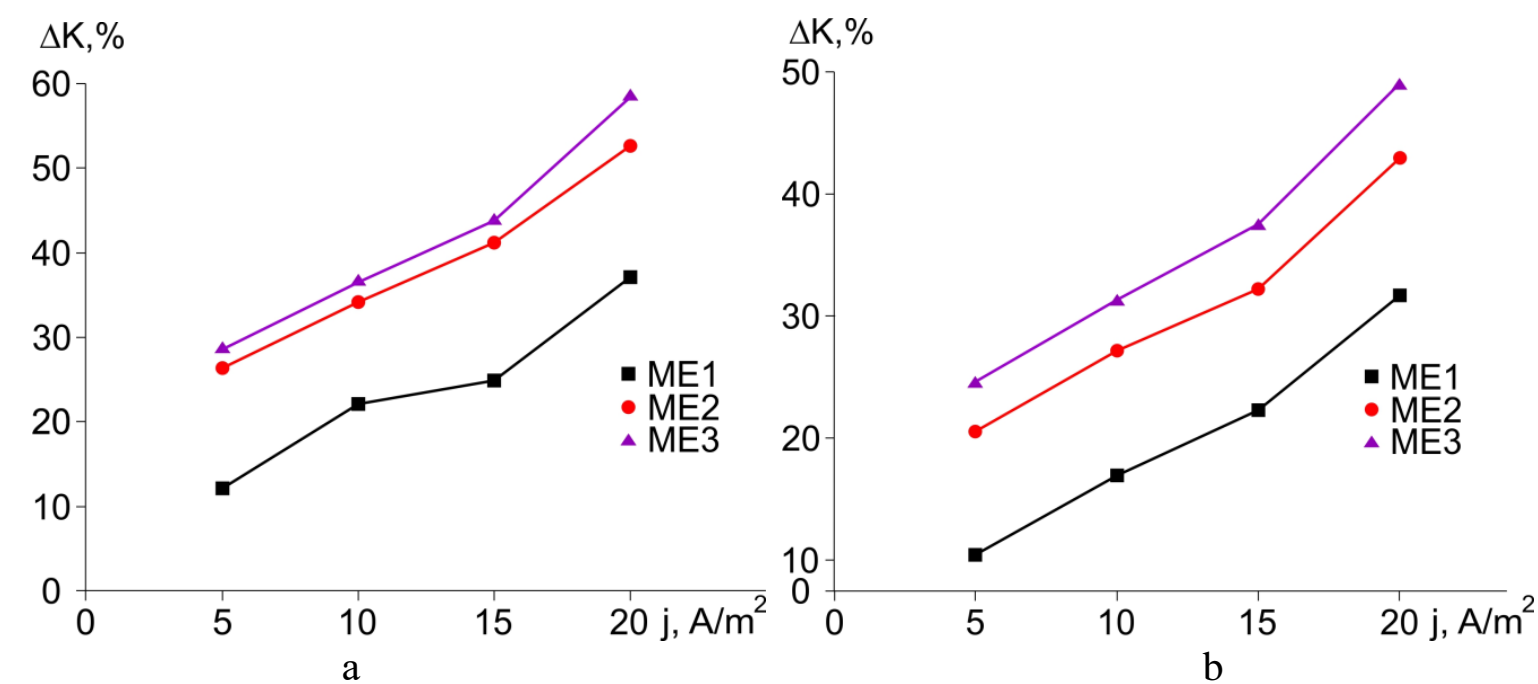

Fig. 4 Dependence of the growth rate of corrosion rate in acidified chloride electrolytes on the value of current density and chemical composition of environment: a - St3, b - 17GS

With a decrease in $\mathrm{pH}$, the mechanism of hydrogen depolarization begins to prevail. Since the ions of the $\mathrm{H}_{3} \mathrm{O}+$ hydroxonium are much more mobile than the oxygen molecules that exist in the soil under good aeration, they act as acceptors of the electrons in neutral and slightly acidic solutions at $\mathrm{pH}=5$. For comparison, the mobility of ions of hydroxonium is $349.8 \times 10-4 \mathrm{~m}^{2} / \mathrm{s} \cdot \mathrm{B}$, ions Cl- is $76.4 \cdot 10-4 \mathrm{~m}^{2} / \mathrm{s} \cdot \mathrm{B}$, ions SO42- is $80.0 \cdot 10-4 \mathrm{~m}^{2} / \mathrm{s} \cdot \mathrm{B}$. The values of the velocities and mobility of the ions are related in a certain way to the size and weight of the ions. Correct regularity of the mobility decrease and electrical conductivity with increase in the sizes of ions (their ion radius) is observed only in the salt melts. In aqueous solutions, this dependence is disturbed by the unequal degree of hydration of ions. The great mobility of hydrogen ions Bernal and Fowler explained by the fact that excess protons contained in aqueous solutions of acids are not fixed by certain molecules of water with which they form ions of $\mathrm{H}_{3} \mathrm{O}+$, but are constantly displaced from one molecule of water (which are dipoles with positive and negative charges at the ends) to another, ie, the current is carried by a jump-free transition of the proton $\mathrm{H}+$ from the $\mathrm{H}_{3} \mathrm{O}+$ ion to the adjacent water molecule (Fig. 5). 


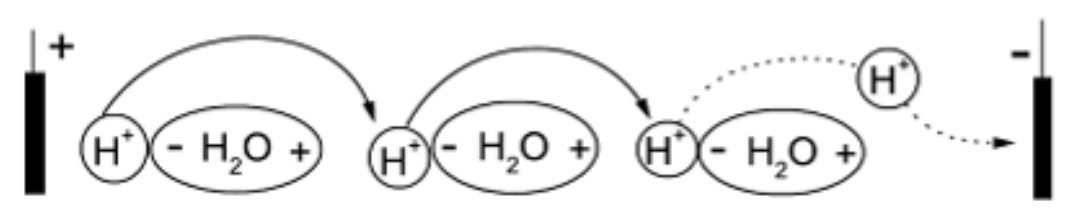

Fig. 5 The mechanism of conductivity of the ion of $\mathrm{H}^{+}$

With such a mechanism of conductivity, the rate of hydrogen ion appears much higher than that of other ions moving in the electric field [22]. As a result, ions of hydrogen are faster than other positively charged ions reaching the surface of the metal and are recovered to hydrogen molecules. Among the acidified chloride environments, the highest rate of general corrosion is observed for ME3. In addition, from Fig. 7 it is seen that with increasing the current density in this environment there is a tendency to further increase in speed. The mass loss at a current density of $5 \mathrm{~A} / \mathrm{m}^{2}$ is $28.7 \%$, and at a current density of $20 \mathrm{~A} / \mathrm{m}^{2}$ in $\mathrm{ME} 3$ at $\mathrm{pH}=3$, it is $58.9 \%$. In many publications, this current density is considered critical, and the probability of corrosion by alternating current is high.

The nature of the damage to surfaces in ME1-3 is different for control samples and specimen under the action of alternating current (Fig. 6). Since bubbles of hydrogen are formed on the surface of the samples under the action of current in ME1-3, but on control samples of their formation are insignificant or not observed at all. In our opinion, this phenomenon is explained by the facilitated adsorption of hydrogen corrosion formed on the damaged surface of the material of the pipeline, especially in places of corrosive cavities and ulcers. This tendency contributes to the additional flooding of the pipe material and the deterioration of its physical and mechanical characteristics, in particular, the reduction of plasticity. As a result, large enough bubbles of hydrogen are formed on the surface, and corrosion ulcers develop along the phase separation surface, which will contribute to the intensive formation of transient corrosive lesions.

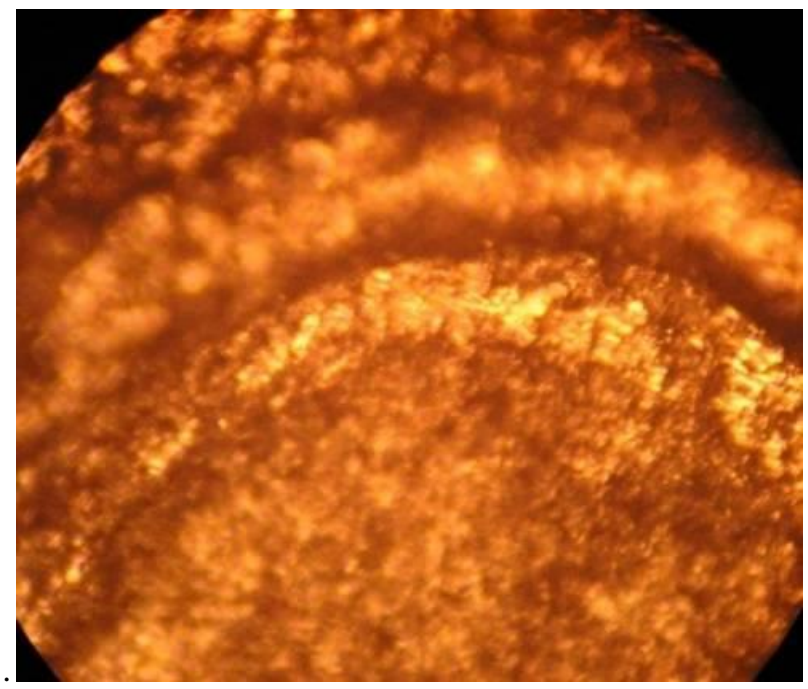

Fig. 6 Characteristic corrosion damage to the pipeline material in acidified chloride environments

The corrosion rate of low-alloy steel $17 \mathrm{G} 1 \mathrm{C}$ in acidified chloride environments is lower than the corrosion rate of carbon steel of St.3 in similar environments of electrolytes in 1.11.3 times, but the general nature of the course of corrosion processes remains the same. The obtained velocity values are $10.4 \%, 20.5 \%$ and $24.5 \%$ in ME1, ME2 and ME3, respectively (Fig. 4). At the final stage of research, determination of the rate of general corrosion in acidified chloride-sulphate electrolytes at different levels of current density was performed (Fig. 7). 

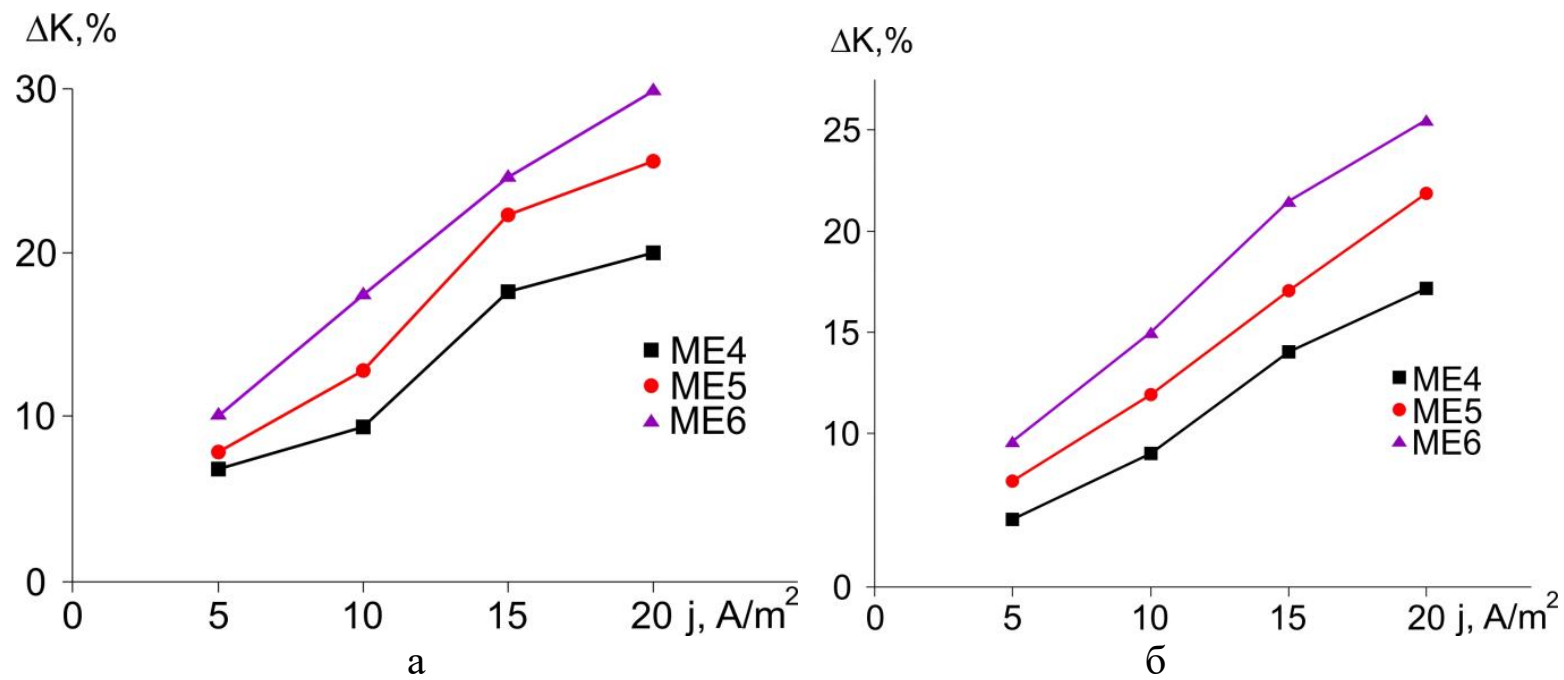

Fig. 7 Dependence of the growth rate of corrosion rate in acidified chloridesulphateelectrolytes on the value of current density and chemical composition of the medium: $\mathrm{a}-\mathrm{St} 3, \mathrm{~b}-17 \mathrm{GS}$

The peculiarity of these environments is the combination of the influence of four factors: chlorides, sulfates, $\mathrm{pH}$ of the medium and the influence of alternating current on the occurrence of corrosion processes. In the case of ME4, the observed dependence is identical to those in neutral chloride-sulphatemedia (ME4-6). Moreover, the rate of general corrosion in ME10 is somewhat lower than in ME4. Although in ME5 $\mathrm{pH}=4$, there is no intense increase in the corrosion rate. Even with an increase in current density up to $20 \mathrm{~A} / \mathrm{m}^{2}$, the increase in speed is $25.6 \%$. In ME6 there is a monotonic increase in the corrosion rate with a tendency for further growth. At the maximum value of current density, the rate of general corrosion is $29.8 \%$, which is slightly different from the value obtained at $20 \mathrm{~A} / \mathrm{m}^{2}$ in ME6 $31.6 \%$.

Similar experimental studies on determining the corrosion rate of low-alloy steel $17 \mathrm{G} 1 \mathrm{C}$ in acidified chloride-sulphatemedia showed a slight decrease in the corrosion rate within 1,0-1,3 times (Fig. 7, b). The character of the velocity change corresponds to that for carbon steels (Fig. 7, a). Experimentally determined growth rates of corrosion rate in ME4-6 are 5.6, 7.7 and $9.6 \%$, respectively.

A visual inspection of the prokaryotic sample (Fig. 8) indicates that the lesions characteristic of these media are the most dangerous in the corrosive aspect. Since on the surface of the test sample, in addition to damage to sulphatemedia, corrosive ulcers are formed due to the formation of hydrogen bubbles, which are concentrated on the metal surface, and then penetrate into the metal, thereby initiating its oviposition and corrosion cracking [23, 24].

The initial stage of hydrogen depolarization is the formation of atomic hydrogen, which diffusing through metal, is recombined and accumulated in various defects of its structure in the form of $\mathrm{H}_{2}$, creating high pressure and significant internal stress [24]. In addition, the hydrogen that is formed significantly accelerates the flaking rate of the protective insulation coating thereby increasing the area of corrosion damage to the metal. It should be noted that on the surface of control samples, as in the case of acidified chloride environments (ME1-3), no significant amount of hydrogen is observed. Thus, in these environments, most local corrosive lesions are possible. 


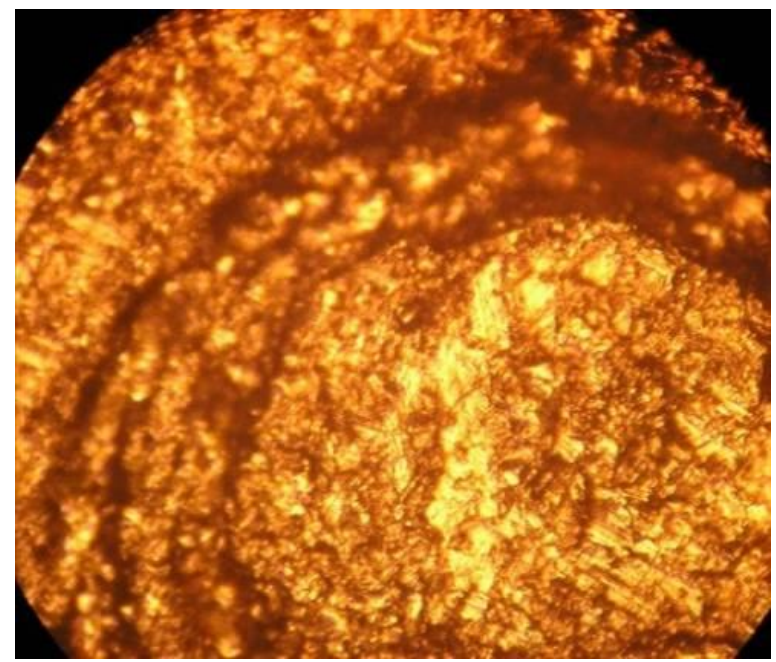

Fig. 8 Characteristic corrosion damage to the pipeline material in acidified chloridesulphateenvironment

The analysis of the experimental results obtained in acidified chloride and chloridesulphateelectrolytes shows that the nature of the change in the growth rate of general corrosion repeats the dependence obtained for neutral chloride and chloridesulphateelectrolytes for the selected range of densities of alternating current (Fig. 9). Characteristic for this diagram is a perceivable increase in the corrosion rate both in acidified chloride and in acidified chloride-sulphate electrolytes, with higher corrosion activity observed in acidified chloride environments relative to ME4-6. For ME3 at a current density of $20 \mathrm{~A} / \mathrm{m}^{2}$, the largest increase in the rate of general corrosion was recorded not only among acidified environment, but also among all electrolytes, namely $58.4 \%$.

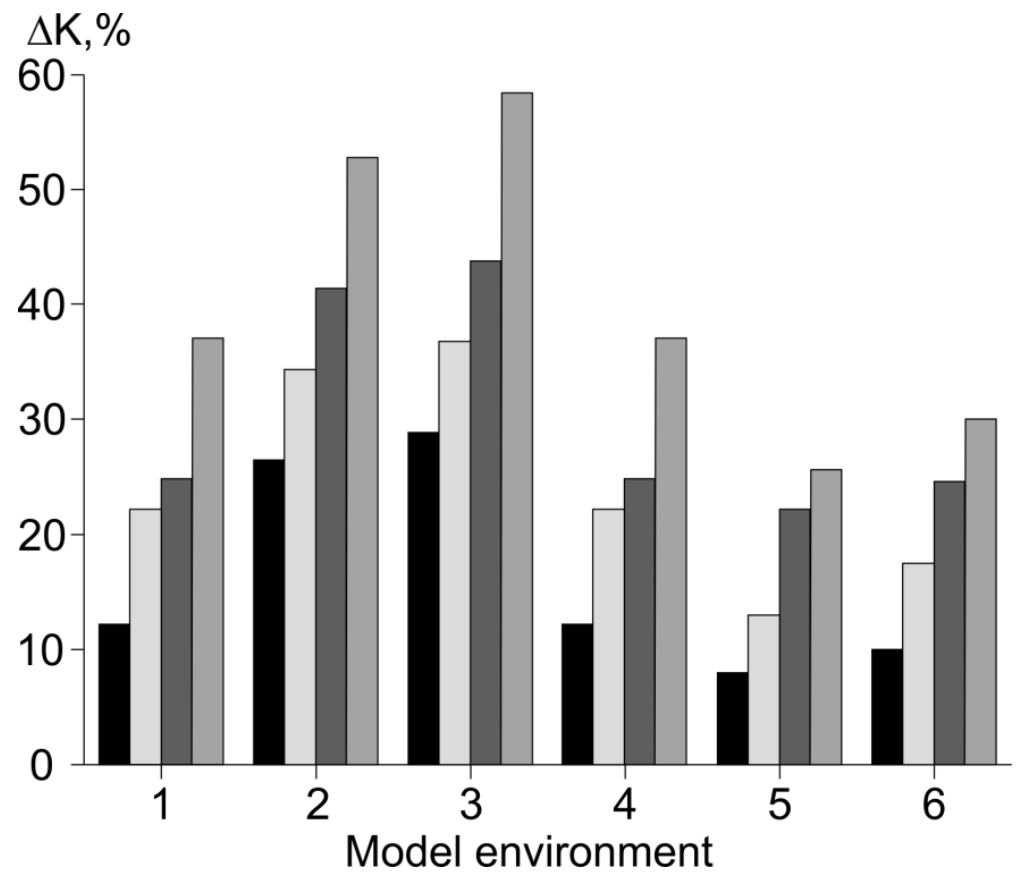

Fig. 9 Dependence of corrosion speed growth rate on the value of current density and the chemical composition of environment.

Thus, as a result of the conducted studies, the most dangerous from the corrosive point of view of the combination of the chemical composition of the soil electrolyte and the vagal current density were established. Such data will minimize losses in gas transportation by taking into account the corrosion factor when choosing new transportation routes and improving corrosion protection of existing pipelines. in the future it is necessary to investigate 
corrosion in the zone of welded joints, which is especially dangerous due to the concentration of residual stresses in the zone of thermal impact [25-27].

\section{CONCLUSIONS}

It was established that the major causes of gas pipeline failures are the corrosion factor and prolonged exploitation. It is shown that the highest risks of depressurization on pipelines with a small thickness of the pipe wall.

The study of electro corrosion in acidic soil electrolytes has been carried out and it has been established that even at a current density of $5 \mathrm{~A} / \mathrm{m}^{2}$ the corrosion rate increases to $30 \%$, which proves the necessity of taking into account such influence.

It has been shown that in acidic mineral soils, the design of new transport corridors for the supply of natural gas is not feasible, and for existing long-exploited gas pipelines it is necessary to implement additional protection against corrosion and increase the frequency of monitoring activities.

\section{REFERENCES}

[1] 9th Report of the European Gas Pipeline Incident Data Group (period 1970 - 2013) https://www.egig.eu/startpagina/\$61/\$156

[2] Prinz, W. "AC induced corrosion on cathodically protected pipelines", UK Corrosion 92, vol.1, pp. 503 - 514, 1992.

[3] Stalder, F. "Pipelines failures”, Materials Science Forum 247, pp. 139 - 146, 1997.

[4] Wakelin, R. G. "AC corrosion - case histories, test procedures, and mitigation" / R. G. Wakelin, R. A. Gummow, S. M. Segall // Conference: Corrosion 98, San Diego CA, USA, Paper number 565, pp. 316 - 324, 1998

[5] Heim, G., Peez G. "The influence of alternating current on buried and cathodically protected high pressure gas pipelines", Gas-Erdgas 133 (3), 1992.

[6] Ragault I. "AC corrosion induced by VHV electrical lines on polyethylene coated steel gas pipelines", Corrosion 98, NACE, paper n557, 1998.

[7] Induced AC Interference, Corrosion \& Mitigation Prepared for NACE / Pipeliners Joint Meeting Atlanta, GA April 8, 2013 Bryan Evans, Vice President, Corrosion \& Integrity Solutions Grayson, GA., 2013.

[8] Wakelin, R.G., Sheldon, C. "Investigation and Mitigation of AC Corrosion on a 300 mm Diameter Natural Gas Pipeline," CORROSION 2004, Paper No. 04205 (Houston, TX: NACE International, 2004), 2004.

[9] Neilsen, L. V., Neilsen, K. V., Baumgarten B., Breuning-Madsen H., Cohn, P., Rosenburg H. "AC-Induced Corrosion in Pipelines: Detection, Characterisation, and Mitigation”, CORROSION 2004, Paper No. 04211 (Houston, TX: NACE International, 2004), 2004.

[10] Peabody A. W. "Control of Pipeline Corrosion", NACE, Second Edition, p. 374, 2001.

[11] The CEOCOR Booklet, "AC corrosion on cathodically protected pipelines. Guidelines for risk assessment and mitigation measures", APCE, p. 44., 2001.

[12] "Guide on the influence of high voltage AC power systems on metallic pipelines", CIGRE Working Group 36.02, 1995. 
[13] Maruschak, P., Poberezny, L., Prentkovskis, O., Bishchak, R., Sorochak, A., Baran, D. "Physical and mechanical aspects of corrosion damage of distribution gas pipelines after long-term operation", Journal of failure analysis and prevention 18(3), pp. 562 - 567, 2018. DOI: $10.1007 / \mathrm{s} 11668-018-0439-\mathrm{z}$

[13] HOST 9.602-2005 «Edynaya systema zashchyty ot korrozyy y starenyya. Konstruktsiyi pidzemni. Zahal'ni vymohy do zakhystu vid korroziyi ».- 55 s. [In Ukrainian]

[14] BN-85/2320-01 Rurociągi stalowe układane w ziemi. Określanie zagrojenia korozyjnego, 1985.

[15] PN-90/E-05030/01 Ochrona przed korozją. Elektrochemiczna ochrona katodowa. Metalowe konstrukcje podziemne. Wymagania i badania, 1990.

[16] PN-EN 12954:2004 Ochrona katodowa konstrukcji metalowych w gruntach lub w wodach. Zasady ogólne i zastosowania dotyczące rurociągów.

[17] CEN/TS 15280, "Evaluation of a.c. corrosion likelihood of buried pipelines Application to cathodically protected pipelines", Technical Specification, CEN European Committee for Standardization, 2006.

[18] Poberezhny, L., Maruschak, P., Hrytsanchuk, A., Mischuk, B., Draganovska, D., \& Poberezhna, L. "Impact of AC current density on material corrosion of distribution pipelines", Koroze a ochrana materialu 61(5), pp. 178 - 184, 2017. DOI: 10.1515/kom2017-0023

[19] Kryzhanivs'kyi, E. I., Hrabovs'kyi, R. S., Fedorovych, I. Y., Barna, R. A. "Evaluation of the Kinetics of Fracture of Elements of a Gas Pipeline after Operation", Materials Science 51(1), pp. 7 - 14, 2015.

[20] Tsyrul'nyk, O. T., Nykyforchyn, H. M., Petryna, D. Y., Dz'oba, I. M. “Hydrogen degradation of steels in gas mains after long periods of operation", Materials Science 43(5), pp. $708-717,2007$.

[21] Speight, J. G. "Lange's handbook of chemistry", (Vol. 1, p. 242). New York: McGrawHill. 2005.

[22] Tsyrul'nyk, O. T., Nykyforchyn, H. M., Zvirko, O. I., \& Petryna, D. Y. “Embrittlement of the steel of an oil-trunk pipeline”, Materials Science 40 (2), pp. 302 - 304, 2004.

[23] Kryzhanivskyy YE. I. "Korroziyno-vodneva dehradatsiya hazotransportnykh system" / YE. I. Kryzhanivskyy, H. M. Nykyforchyk // Naukovi zapysky. - 2013. - Vyp. 41 (1). pp. 148 - 153, 2013. [In Ukrainian]

[24] Uorf, R.A. "Otsinka korroziynoyi aktyvnosti seredovyshch Salymskykh naftovykh rodovyshch $\mathrm{z}$ tochky zoru mozhlyvostey vyklykaty sulfidne rozshcheplennya promyslovykh truboprovodiv ta obladnannya" / R.A. Uorf, A.B. Kychenko // Praktyka protykorrozyonnoyi zakhystu. - 2012. - № 1 (63). - pp. 42 - 49, 2012. [In Russian]

[25] Moi, S. C., Pal, P. K., Bandyopadhyay, A., Rudrapati, R. "Determination of Tungsten Inert Gas Welding Input Parameters to Attain Maximum Tensile Strength of $316 \mathrm{~L}$ Austenitic Stainless Steel” Journal of Mechanical Engineering - Strojnícky časopis 68 (3), pp. 231 - 248, 2018. DOI: 10.2478/scjme-2018-0037

[26] Kumar, N., Mukherjee, M., Bandyopadhyay, A. "Study on laser welding of austenitic stainless steel by varying incident angle of pulsed laser beam", Optics \& Laser Technology 94, pp. 296 - 309, 2017. DOI: 10.1016/j.optlastec.2017.04.008 
[27] Valkovič V., Jančo R., Frydrýšek K. "The effect of landslide on gas pipeline”, Journal of Mechanical Engineering - Strojnícky časopis, 66 (2), pp. 95 - 100, 2016. DOI:10.1515/scjme-2016-0023 